\title{
ELIXIR ALS PAARDENMIDDEL
}

\section{Luc Devriese}

\section{SAMENVATTING}

Elixirs ontstonden in een alchemische context en werden vanaf de $16^{\text {de }}$ eeuw populair in de geneeskunde. Tegen het einde van de $19^{d e}$ eeuw verlieten ze de apotheek. Geneverstokers zagen er een middel in om hun alcoholica een heilzame en sterkende reputatie te geven. Ook in de diergeneeskunde werden elixirs aanbevolen door de $17^{d \theta}$-eeuwse en latere peirdemeesters vooral voor darmproblemen (de gevreesde koliek) bij paarden en meteorisme bij herkauwers. Aan de veterinaire faculteiten verdedigden sommige farmacologen alcoholische dranken als geneesmiddel. Omstreeks het midden van de twintigste eeuw geraakten ze in onbruik in de diergeneeskunde.

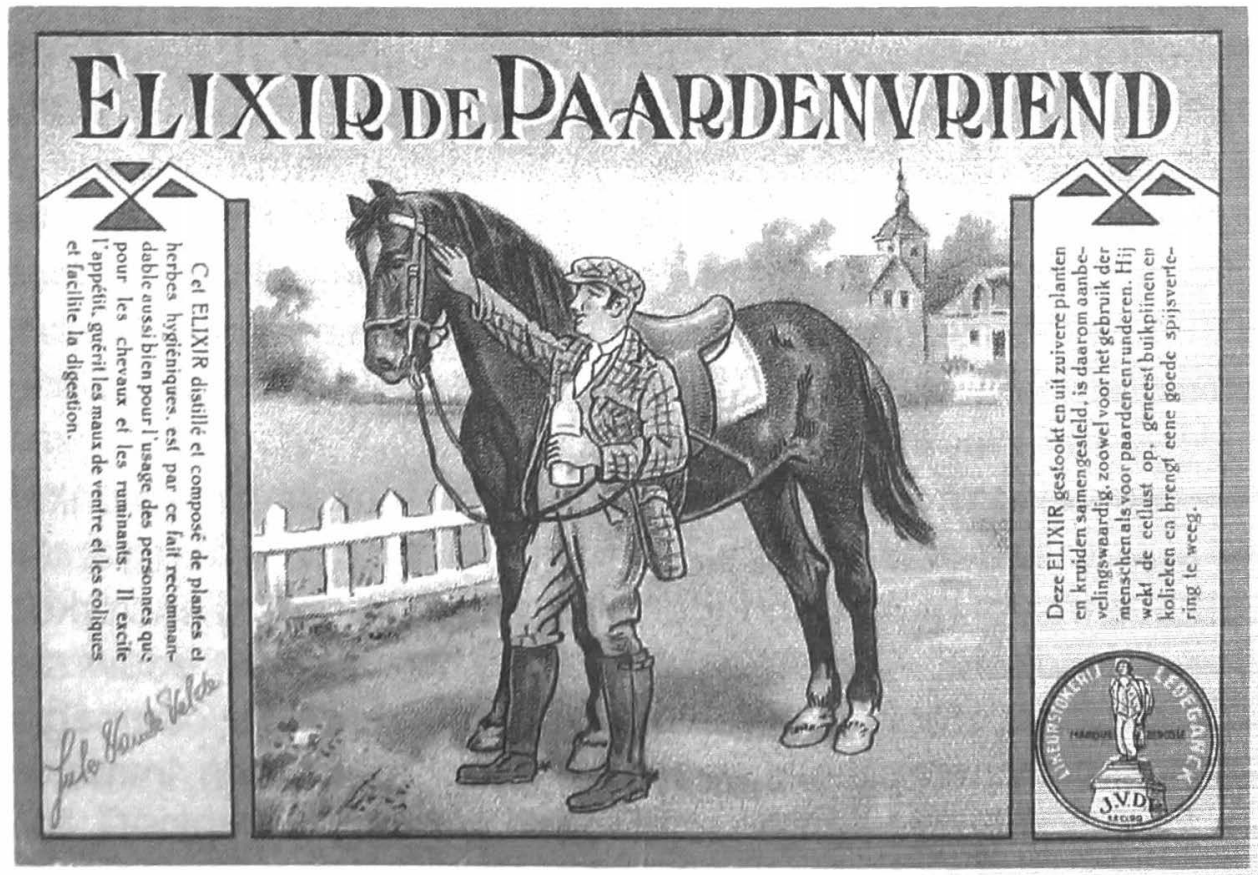

Elixirflesetiket met indicaties voor diergeneeskundig gebruik (Verzameling Nationaal Jenevermuseum Hasselt) 


\section{INLEIDING}

Het woord elixir heeft zowat de meest geheimzinnige inhoud en betekenis die men zich kan inbeelden. Het bevat het Arabische lidwoord al -ook in alcohol, alchemie en alambiek - en de Arabische verbastering (iksir) van het Griekse werkwoord voor drogen to xèrion. Hiermee werd het maken van de beruchte Steen der Wijzen beoogt, noch min noch meer. Dat zou gebeuren via "drogend" of transformerend poeder, "zaad of geest van goud". De kleinste hoeveelheid hiervan, zo dacht men, was in staat alle andere metalen onmiddellijk in goud om te zetten. Het was dit poeder dat de alchemist in zijn distillatie-, condensatie- en sublimatietoestellen probeerde te reproduceren (De Ley, 1993). De elixirs die we nu kennen namen daarvan heel prozaïsch enkel de goudgele kleur over. Het prototype ervan stamt uit de $16^{\text {de }}$ eeuw en omvatte slechts drie ingrediënten: aloë, mirre en saffraan met brandewijn als oplosmiddel. In die tijd bestond er enorm veel belangstelling voor destillaten allerhande. De destillatie met alambiek bezat nog alchemistische betovering en een beetje daarvan bleef hangen in het geneeskundige gebruik van elixirs als panacee (goed voor alles) dat toen ontstond. Vandaar ook het begrip "levenselixir". Farmacologisch actieve stoffen werden opgelost in brandewijn, een optimaal oplosmiddel voor essencen en andere al of niet werkzame bestanddelen dat bovendien zelf - het zal niemand onbekend zijn - inwerkt op sommige functies. Bijkomend en zeker niet te onderschatten voordeel van alcohol in de oude farmacie was het verhinderen van schimmelen. Waterige destillaten waren daar in de onmogelijk te reinigen aardewerken kruikjes van toen maar al te gevoelig aan.

In tegenstelling tot andere alcoholdestillaten die oorspronkelijk ook als geneesmiddel bedoeld waren, bleven elixirs hun gezonde reputatie min of meer behouden. Aanvankelijk bereid en verkocht door apothekers, werden ze aan einde van de $19^{\text {de }}$ eeuw sterk gepropageerd door de jeneverstokerijen. Door de campagnes tegen het drankmisbruik was hun kernproduct toen immers in een kwalijk daglicht komen te staan.

Elixirs van bekende en minder bekende merken werden niet alleen populair als geneesmiddel en genotmiddel voor mensen. Ook bij dieren werden ze toegepast als geneesmiddel, vooral 
voor darmproblemen bij paarden. We mogen aannemen dat het aspect 'genotmiddel' hier beperkt bleef tot het eventueel meegenieten van een slokje door de personen belast met het toedienen van de drankjes aan de beesten. De smaak en de geur van geneesmiddelpreparaties voor dieren die met het voer of in het drinkwater toegediend worden is soms een moeilijk punt. Sommige diersoorten of zelfs individuele dieren kunnen een sterke afkeer vertonen voor bepaalde smaken, geuren en kleuren en zieke dieren kunnen nog minder dan mensen overtuigd worden om te eten en al helemaal niet om spontaan een geneesdrankje in te nemen. Zelfs als de elixirs min of meer lekker of neutraal smaakten voor een paard of een koe, moesten ze aan zieke dieren 'opgegoten' worden met behulp van metalen drinkbussen voorzien van een lange tuit. Wat niet zonder dwang kon gebeuren.

\section{VOOR KOLIEKEN EN TROMMELZUCHT}

De elixirs bestemd voor dieren werden onder andere verkocht in apotheken. Een advertentie uit 1905 van Apotheek Picard in de prestigieuze Gentse Veldstraat voor Elixir Hippophile (hippofiel = paardenlievend) prees het product aan als Het eenigste middel hetwelk oogenblikkelijk de hevigste krampen en buikpijnen van de paarden en het vee stilt. Bijna de helft (40 per honderd) der sterfgevallen bij de paarden zijn veroorzaakt door de kolieken. De eerste bewering moeten we laten voor wat ze waard is, maar de tweede benadert zeker de waarheid. De uiterst pijnlijke kolieken of darmkrampen verlopen bij paarden dikwijls dramatisch en fataal. Wie ooit zoiets meegemaakt heeft, vergeet het nooit. Actueel brengen operatieve en andere ingrepen in veel gevallen genezing (Steenhaut e.a., 2000), maar de aandoening blijft problematisch.

Bij runderen was de voornaamste indicatie voor het gebruik van elixirs meteorisme of trommelzucht. Ook dit is een dramatisch gebeuren. In het populaire werkje De Geneesheer der Armen door Doctor Beauvillard dat ook diergeneesmiddelen opnam, propageerde het Elixir météofuge d'Alfort. Den Elixir mengt zich met de schadelijke dampen en vernietigt ze, lezen we. De opgeblazenheid (meteoros: Grieks voor opgeheven) wordt 
Uit De Geneesheer der Armen ('nieuwe' uitgave 1929), een populair werk je van Franse origine over huisgeneesmiddeltjes en commerciële preparaten dat ook enkele diergeneeskundige aspecten behandelt.

afgedreven (fugein: Grieks voor vluchten). De naam en de reputatie van Frankrijk's bijzonderste veeartsenijschool (Alfort bij Parijs) werden hier ook even 'geleend' om die bewering kracht bij te zetten.

Hiermee is het toepassingsgebied van de elixirs bij dieren grotendeels geschetst: darmproblemen, met kolieken bij paarden en trommelzucht bij herkauwers als meest spectaculaire en veel voorkomende aandoeningen

De toepassing van elixirs bleef echter grotendeels buiten de reguliere diergeneeskunde. De drankjes werden vooral gebruikt door paardenkenners, paardenboeren en, niet in het minst, door voerlui en stedelijke koetsiers, de dikwijls nogal speciale mannen van de 'fiakers'. Zo werden in Oostende in de periode rond de wereldoorlogen elixirs opgegoten aan paarden die aan wal kwamen met diarree na een min of meer woelige 
zeereis uit Engeland of lerland. In de $19^{\mathrm{de}}$ - en $20^{\text {ste }}$-eeuwse diergeneeskundige handboeken werden de typische elixirs totaal genegeerd. Het therapeutisch (bedoelde) gebruik van alcohol bij dieren waarop de diergeneeskundige toepassing van de drankjes stoelde, werd echter in dezelfde handboeken uitvoerig beschreven. In het hiernavolgende wordt vooral aan dit aspect aandacht besteed.

\section{AANBEVOLEN DOOR PEIRDE-MEESTERS}

In de oudste gedrukte en sterkst verspreide Nederlandse diergeneeskundige tekst kwamen elixirs en andere alcoholische bereidingen nog niet aan bod. Het betreft de Meesterije voor de Paerden ... of Hulpmiddelen voor de Peirden... die in de $16^{\text {de }}$ eeuw gedateerd werd (Braekman, 1987). Dat werkje werd tot in de $18^{\text {de }}$ eeuw in diverse varianten uitgegeven, telkens met de aanduiding dat de beschreven geneeswijzen in gebruik waren bij de keizerlijke maarschalk, de hoofdverantwoordelijke voor de paarden aan het hof te Brussel. Evenmin was er sprake van alcohol of andere elixircomponenten bij de bespreking van koliekbehandeling in het Latijnse werk Libri duo Philippicorum van de medicus Pieter van Naaldwijck verschenen in 1631. Dat steunde op klassieke teksten en vooral op de $14^{\mathrm{de}}$-eeuwse Hippiatria van Laurentius Rusius, het hoogtepunt van de middeleeuwse paardengeneeskunde.

In de belangrijke en veel gebruikte Nederlandstalige veterinaire 17de-eeuwse drukwerken samengesteld door niet klassiek geschoolde Peirde-Meesters uit onze streken lag dat echter anders. De Toevlugt of Heylsame Remedien voor alderhande Siektens en Accidenten die de Paerden soude konnen overkomen van Pieter Alemanus van Coer (of van Cour), meester hoefsmid te 's Gravenhage (1 ${ }^{\text {ste }}$ uitgave 1688), vermeldde brandewijn met verschillende toevoegingen als middel bij uitstek voor de genezing van Colyk ofte Buyck-pyne. Zo werden aanbevolen: Zevenboom (Juniperus sabina) in jeneverwater, eierdooiers in brandewijn en Driakel (theriacum: legendarische, niet onschuldige mengsels van allerlei stoffen die beschouwd werden als tegengiffen) eveneens in brandewijn naast anijs, venkel en komijnzaad samen met Nagelgruys (Gneum soorten, Nagelkruid) en brood gekookt 


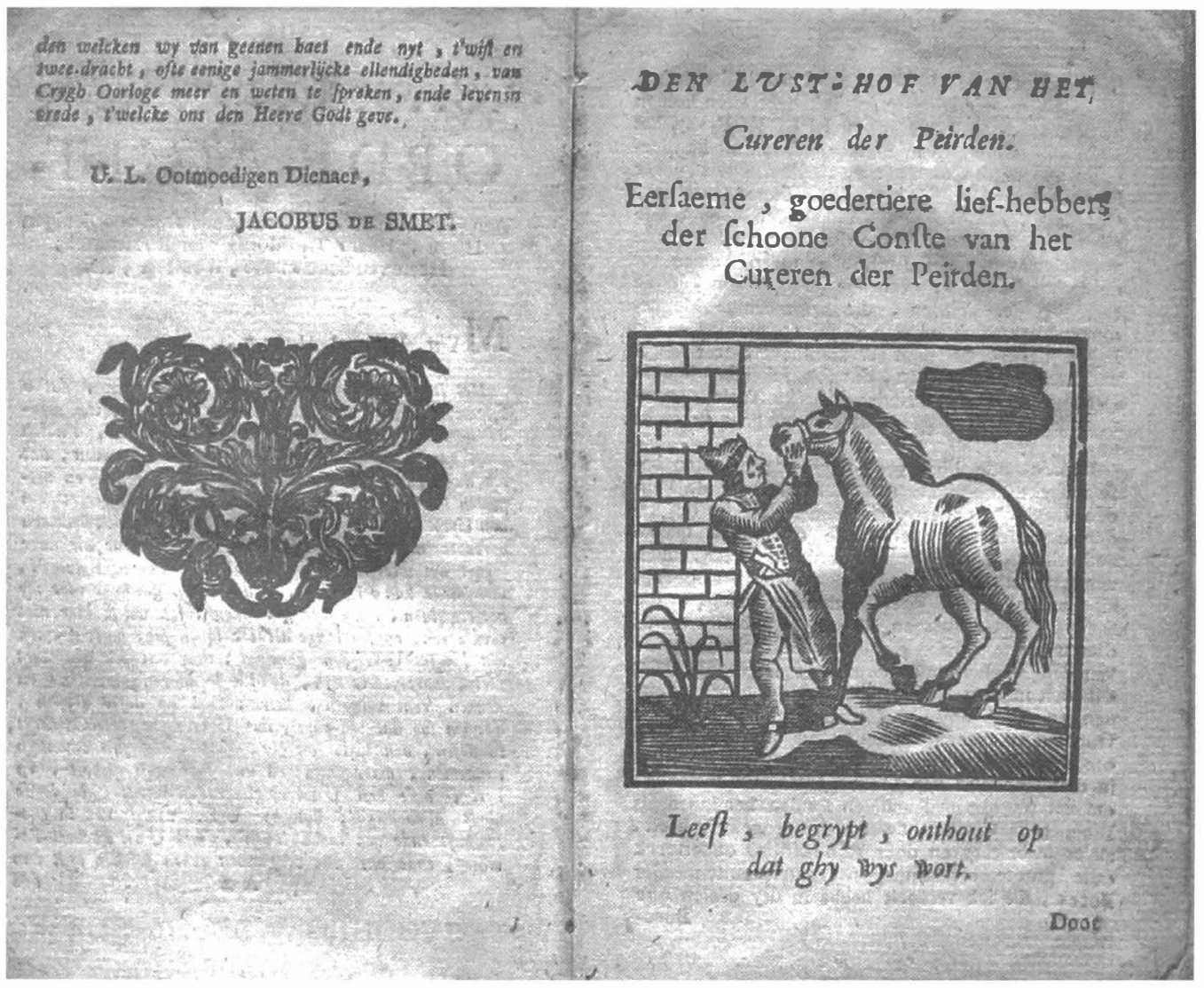

Den Lusthof van het Cureren der Peirden door Jacobus de Smet (eerste druk 1686) bevat de oudste ons bekende Nederlandstalige aanbevelingen voor het gebruik van elixir bij dieren.

in bier. De voornaamste diergeneeskundige indicatie (koliek) is

er en sommige ingrediënten beginnen er al naar te ruiken, maar elixirs kan men de middeltjes van meester van Coer bezwaarlijk noemen.

Elixirpreparaties kwamen wel aan bod in Den Lust-Hof van het Cureren der Peirden beschreven door Mr. Jacobus de Smet, Peirde-Meester in Borgerhout, buyten de Stadt Antwerpen, waarvan de eerste druk in 1686 te Antwerpen verscheen. Hoewel ook hierin de elixirs er niet bij naam in genoemd werden, blijkt uit de voorschriften dat de alcoholische geneesdrankjes wel degelijk die naam verdienen:

Brandewyn om te purgeren. Neemt een pinte Brandewyn, doet daer een once (23g) Jalap (jalappe hars, verkregen uit een van oorsprong Mexicaanse plant, krachtig purgeermiddel en vochtafdrijvend), een once Briona (Bryonia, heggerank, planten 
van de komkommerfamilie, volgens de Smet in Brabant wilde wingerd en in Vlaanderen schyt-raepen genoemd), een drachma $(2,9 \mathrm{~g})$ soffraan van noorden (Curcuma, het betaalbare alternatief voor saffraan), alles fijn gepulveriseert synde. Dat moest samen met honing en regenwater aan een fles brandewijn toegevoegd worden.

Water clerette. In nog een tweede recept werd kaneel, muskaatnoot en kruidnagel aan den stercksten Brandewyn van wyn toegevoegd en met een derde deel rozenwater vermengd. Die preparatie was vooral geschikt voor kraamvrouwen om de moeder te suyveren, t'herte te verstercken, ende heeft seer veel krachten om de nae-wee-en te verdryven.

De preparaten op basis van brandewijn werden volgens de Borgerhoutse auteur bij voorkeur 's morgens nuchter gedronken. Zo ingenomen waren ze zeer goed tegen de pyne in't herte. De wormen in de maege deden ze stillen. In tijden dat de gaeve Godts ofte Peste regneert, konden ze de quaede lochten ende venynige (giftige) dompen tegengaan. Ook voor de urinewegen boden de brandewijnmengsels verlichting. Ze waren mede goet tegen de koude pisse ofte graveel en ze bevorderden de urinelozing. Van de brandewijn met Jalappe, Bryona en Curcuma mocht men een, twee of drie lepels innemen naer de sterckte van de persoon. Dat maeckt seer wel camerganck (ontlasting). Het purgeert alle galachtige, slymige en waterachtige slechmalycke humeuren (vochten). Het opent de verstoptheyt van de lever, loose (longen) ende milte. Het doet de winden scheiden van de maag en de darmen en nog veel meer.

We moeten de man op zijn geschreven woord geloven want de Peirde-Meester voegde er ongegeneerd aan toe dat hij het zelf beproefd ende zeer wel bevonden had bij diversche persoonen die van ander Doctoren verlaten waren. En wat goed was voor mensen was vanzelfsprekend goed voor dieren. Dat gold ook voor alcohol. Brandewijn doet de maege wel koken, de spyse wel verteiren. Maar dan moest hij wel bereid zijn zoals hierboven aangegeven: onder elixirvorm of als likeur. Dat vermelde de Smet er uitdrukkelijk bij.

Ook de heel wat duurdere en chiquere collega van onze 
Borgerhoutse Peirde-Meester, Monsieur François-Alexandre de Garsault, Capitaine des Haras (stoeterijen) du Roi (van Frankrijk), had het voor elixir. In zijn Nouveau parfait Maréchal (eerste uitgave 1741), gaf hij een recept van brandewijn, theriak, saffraan en laudanum ten beste als middel tegen darmproblemen bij paarden. Als antidiarree middel had deze militair een 'élixir de propriété' in zijn mars. Dat was het standaardtype met mirre, aloë en saffraan. De invloed van deze beschrijvingen mag niet onderschat worden. Het werk van de Garsault was in de $19^{\text {de }}$ eeuw wellicht de meest gebruikte gezaghebbende bron van paardenkennis in Europa.

\section{PAARDENGENEESMIDDEL OF 'PAARDENMIDDEL'?}

Bij de bespreking van de uitwerking van de recepten vergat Jacobus de Smet dat hij verondersteld werd diergeneesmiddelen aan te geven, en hij beschrijft doodleuk hoe goed mensen er mee voeren. Meester de Smet kopieerde zijn humane collega's. Dat was typisch. De veterinaire auteurs namen zelfs de moeite niet het woord 'mens' te vervangen door 'dier'. Ze weken enkel af van wat ze in humane handboeken en voorschriften vonden in de specifieke beschrijvingen van de symptomen en het verloop van enkele erg typische dierenziekten. Voor wat de geneesmiddelen betreft, hielden ze zich angstvallig aan wat er in de humane sector (verondersteld) gekend was.

284 Maar meester de Smet, schijnbaar heel wat meer onderlegd in de basiswetenschappen dan zijn eveneens schrijvende Nederlandstalige collega's en goed op de hoogte van de paardenanatomie, gaf er een uitvoerige en niet mis te verstane waarschuwing bij. Ze werpt een wat ander licht op wat we nu verstaan als een 'paardenmiddel'. Paarden, zo stelt de Smet, zijn door de bouw van hun darmstelsel uiterst gevoelig aan alle purgeerende ofte sweet-maeckende medicamenten. Hun dikdarm en blinddarm zit vol ingestamt ofte geperst met grove spijzen, hooi en gras, waardoor de medicamenten niet kunnen booren ofte door-breken. Gevolg daarvan is dat ze als hete en giftige dampen snel opgenomen worden in het chilum (darmslijm) en den ommeloop des bloets naar de lever en het hart. Deze heete en fenynige (giftige) dampen benauwen en 
versmachten het hart. Net zoals een vier ofte kersse, die door den domp, roock ofte ander verstoptheye geen locht en krygt ende alsoo ten laetsten uyt dompen moet. Meester de Smet liet er meteen op volgen: daarom en behoort men de peirden geene stercke ... medicamenten in te geven en hij adviseerde de bij mensen gebruikelijke doseringen van dergelijke preparaten sterk te verlagen. Hij waarschuwde zelfs zijn collega's niet enkel voort te gaan op de kennis van de apothekers die zich al te zeer op ervaringen met mensen baseerden. De mensendarm is immers gevuld met fynder ende veel weecker spyse die veel lichter scheyden. Ook raadde de Smet aan de toedieningen te fractioneren: alsoo sal men altydt sonder perykel werken. Onze auteur stelt uitdrukkelijk dat hij in zijn boek geen sterke of

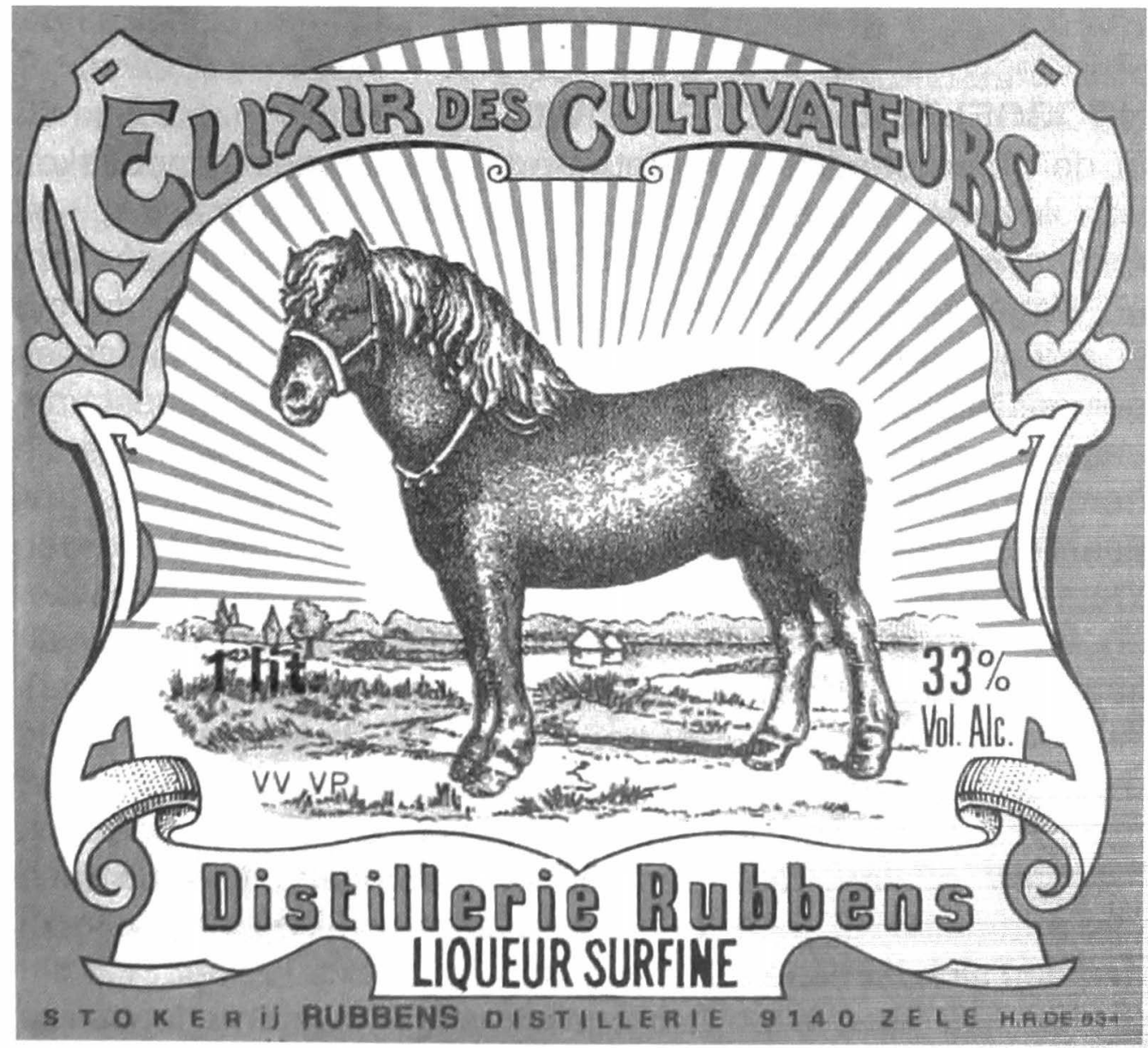

285

Elixirflesetiket met indicaties voor diergeneeskundig gebruik (Verzameling Nationaal Jenevermuseum Hasselt) 
gevaarlijke medicamenten wilde opnemen: om dat ick by sommige Smits veel ongelucken hebbe weten te geschieden. Tussen de regels door lees je dat hij zelf ook al een en ander mee gemaakt had. Maar, zo verzekert Jacobus, met wat in zijn boek staat en sal men nemmermeer geen peirden met sulcke drancken doodt doen, daar ick se meer als duysentmaels beproeft hebbe.

Primam non nocere (in de eerste plaats niet schaden). Dat was en is de voornaamste regel van de geneeskunde. Het was en is geen gemakkelijk te volgen regel. Hoewel de theorie van de Borgerhoutse paardenmeester gesteund was op goede anatomische observaties en een up-to date kennis van de bloedsomloop - beschreven bij mensen door Harvey in 1628, ligt het niet zo eenvoudig. Maar zijn gevolgtrekkingen zijn juist te noemen. Jacobus de Smet was een wijs man, blijkbaar.

\section{HOOGGELEERD ONDERBOUWD}

In de veel gebruikte $19^{\text {de }}$-eeuwse vulgariserende handboeken van Numan (oorspronkelijk Nederlands getrokken uit onderscheidene in en uitlandsche vee-artsenijkundige schriften) en Wagenfeld (vertaald uit het Duits), aanwezig op tal van grote boerderijen en paardenhouderijen, bleven de oude indicaties gelden. Numan schreef enkel brandewijn met water en gestampt anijs- en venkelzaad voor bij acute en chronische recidiverende trommelzucht bij runderen en schapen en 'windkolieken' bij

paarden veroorzaakt door het eten van te veel jong groenvoer. Wagenfeld meende dat bij trommelzucht dranken van zeepwater en brandewijn, van pekel met brandewijn, en aftreksels van kamille, anijszaad en venkelzaad verlichting zouden brengen. Andere indicaties waren er voor hem niet. Bij Wagenfeld en in de latere uitgaven van Numan's handboek worden echter ook al meer efficiënte middelen beschreven voor acute trommelzucht: het gas aflaten met een buisje doorheen de buikwand ('trocardmethode', meestal met buikvliesontsteking tot gevolg) of met een slokdarmsonde.

In de $19^{\mathrm{de}}$-eeuwse diergeneeskundige wetenschappelijke literatuur, bij ons overwegend van Franse herkomst of gebaseerd op Franse bronnen, is er geen sprake meer van elixirachtige preparaties. Tabourin beschreef rond 1850 in zijn Nouveau Traité 
de Matière Médicale voor dierenartsen vrij nauwkeurig de acute toxische effecten van alcohol bij huisdieren. Vooral paarden en honden blijken gevoelig te zijn. Volgens dezelfde auteur werd alcohol tamelijk frequent uitwendig gebruikt, vooral om bloed te stelpen en wonden te laten opdrogen. Al wist men dat de wonden moesten gezuiverd worden, van disinfectie had men geen notie. Hoewel alcohol volgens deze Franse auteur eerder zelden inwendig toegepast werd, beschreef hij het gebruik van brandewijn en wijn in detail. Cider en bier werden even aangehaald, maar van elixirs was er geen sprake. De Brusselse veterinaire farmacoloog Dupuis vermelde ze een halve eeuw later evenmin in zijn cursus en hij gaf aan dat men sommige tincturen en andere preparaten foutief elixir noemt. Zo bijvoorbeeld het elixir parégorique (paregorisch: verzachtend, pijnstillend), in werkelijkheid een opiumtinctuur.

Ondanks dit negeren van de elixirs door de hooggeleerde farmacologen van die tijd, kon men in hun werken toch een rechtvaardiging vinden voor het gebruik ervan. Tot in de dertiger jaren van de vorige eeuw werd daarin immers alcohol aanbevolen voor allerhande aandoeningen, telkens met maagdarmproblemen voorop. In het Vadémecum du Vétérinaire dat in de eerste helft van de twintigste eeuw talrijke herdrukken beleefde, raadde men bij paard en rund 150 tot 300 g. $40-50 \%$ alcohol aan als koortswerend middel en exitans. Voor de sémi-anesthésie van een rund van 600 tot $800 \mathrm{~kg}$. had men twee tot drie liter van doen. Er was enkel sprake van eau-de-vie of rum. In de uitvoerige monografie Die Kolik des Pferdes van de Beierse dierenarts Ariess uit dezelfde periode werden dit soort bereidingen als onwerkzame maar weinig schadelijke huismiddeltjes afgedaan. Of de stoffen die door de auteur wel aanbevolen werden, zoveel beter waren, mag wel betwijfeld worden.

André Vanden Eeckhout (1873-1953), na W.O. I professor aan de toen nog enige Belgische veeartsenijschool te Kuregem (Brussel) was echter van een andere mening. Deze somde niet minder dan elf indicaties op voor diergeneeskundig gebruik van alcohol. De stof was maagstimulerend, antispasmodisch (tegen darmkrampen of kolieken) en versterkend (cognac met kippenbouillon!). Het hielp tegen vermoeidheid, het was hartstimulerend, koortswerend, opwarmend en fluimafdrijvend. 
In kleine doses was alcohol een afrodisiacum en in hoge een narcoticum. Ook bij zware verlossingen was het goedje nuttig. Voor een koe raadde de Brusselse professor $800 \mathrm{~g}$ tot één liter 30\% gewone eau-de-vie @30\% aan.

Professor Vanden Eechout gaf zelf (in zijn cursus tenminste) de voorkeur aan cognac in koffie: dans les cas de coliques par spasmes, de coliques venteuses (trommelzucht) ou par indigestion, nous prescrivons volontiers un mélange composé de 200 à 250 grammes de cognac et d'un litre d'infusé de café. En hij voegde er aan toe: Ce breuvage (drankje) présente le grand avantage de ne nuire en rien à la qualité de la viande. lets waar niemand zal aan twijfelen. Zuivere ethylalcohol moest één op drie verdund worden. Het was echter beter alcoholische dranken zoals likeuren te gebruiken. Of ze ook beter waren dan cognac of rum, liet de professor in het ongewisse.

Daarmee was de basis gelegd. Het enige wat de elixirfabrikanten nog moesten doen, was via hun reclame en hun fraaie etiketten de elixirs zoveel mogelijk de plaats van de pousse-café en de jenever als paardenmiddel te laten innemen.

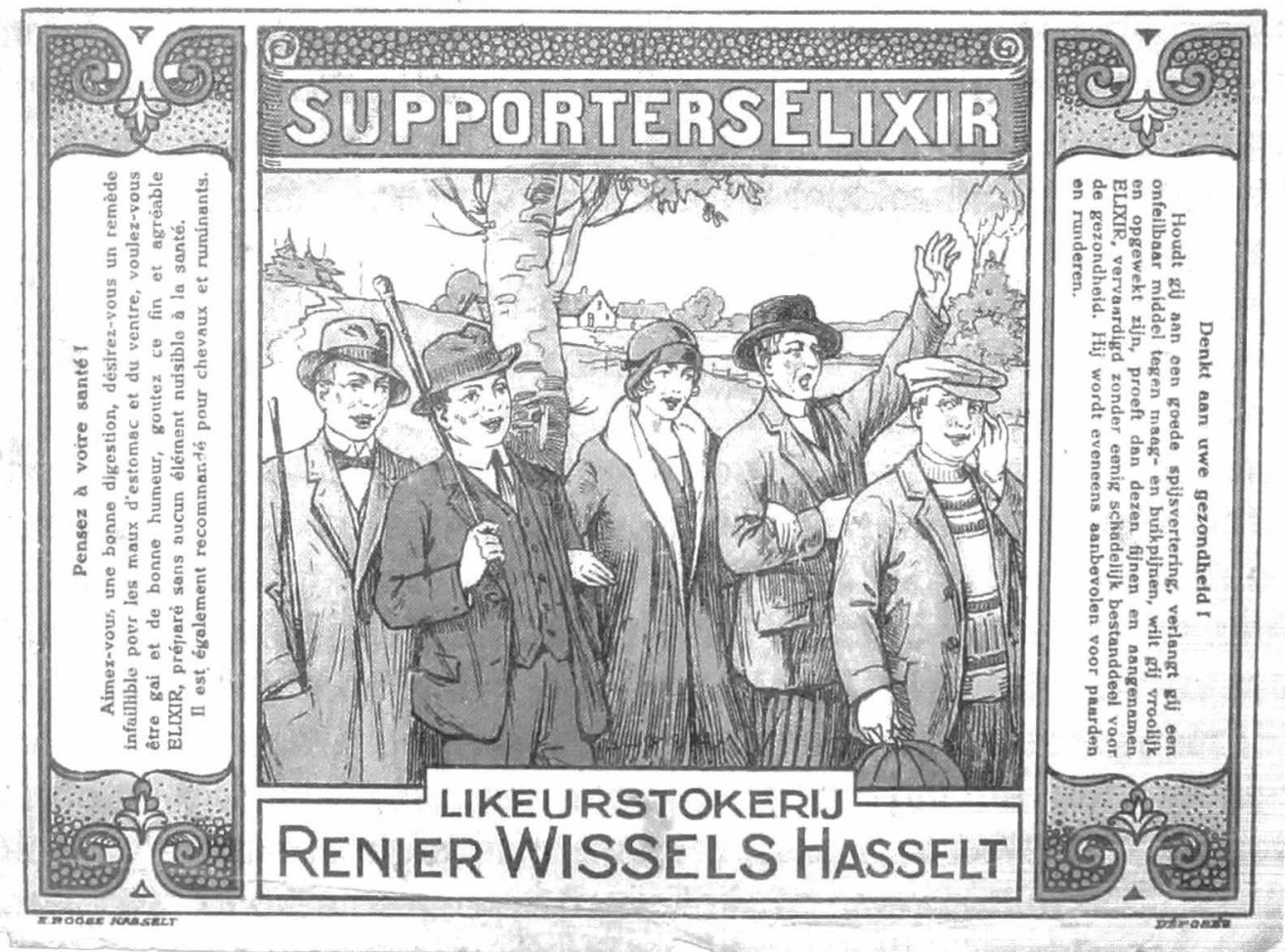

Elixirflesetiket met indicaties voor diergeneeskundig gebruik

(Verzameling Nationaal Jenevermuseum Hasselt) 


\section{Dankbetuiging}

Dank aan Johanna Janssen (Gent) voor haar inlichtingen over Oostendse paardentoestanden in het Interbellum en aan de medewerkers van de Hasseltse tentoonstelling die de aandacht vestigden op het destijds wijdverspreide gebruik van elixirs bij dieren. Ze zetten daarmee de auteur van dit artikel op het spoor van een totaal onvermoed aspect van de veterinaire geschiedenis. De oorspronkelijke versie verscheen in het Vlaams Diergeneeskundig Tijdschrift;

\section{LITERATUUR EN BRONNEN}

Anomiem (s.d.). Hulpmiddelen voor de Peirden, om te weten alle de geheymen alzoo men die gebruykte by den Marschalk des Keyzers ende Ards-Hertogen Keyzer Karel den V. In de versie samen met het werk van P.A. van Cour uitgegeven te Brugge in 1722, pp. 54.

Ariess, L. (1927). Die Kolik des Pferdes und ihre Behandlung, Stuttgart, p. 215.

Braekman, W.L. (1997). Zestiende-eeuwse veterinaire literatuur uit de Nederlanden, Reeks Scripta, nr. 20, Brussel, pp. 178.

de Garsault, F.A. (1797). Le Nouveau Parfait Maréchal, vijfde uitgave, Parijs, p. 214 en 452.

De Ley, H. (1993). Syllabus Ugent: Het klassieke Arabische denken. Deel 1, Gent, p. 140-145 (ook in www.flwi.ugent.be/Cie/ RUG/deley25.htm).

de Smet, J. (s.d.). Den Lust-Hof van het Cureren der Peirden (Antwerpen), vierde druk, p. 271-275 en 286-287.

De Geneesheer der Armen en de 2000 nuttige recepten door Doctor Bauvillard (1929), nieuwe uitgave (vertaling), Brussel, $p$. 158-159.

Dupuis, G. (1907). Précis du Cours de Pharmacologie, Brussel, p. 46.

Mollereau, H. (1931). Vadémécum du Vétérinaire, zevende druk, Parijs, p. 68,.

Numan, A. (1826 en 1866). Handboek der Genees- en Verloskunde van het Vee (Groningen), tweede druk, p. 209, 350 
en 495; zesde druk, , p. $289-292$.

Steenhaut, M., Martens, A., Vlaminck, L., Gasthuys, F., Desmet, P., Demoor, A., Mariën, T., Deprez, P. (2000). Koliek bij het paard: een retrospectieve studie, Vlaams Diergeneeskundig Tijdschrift $69,24-30$.

Tabourin, M.F. (1853). Nouveau Traité de Matière Médicale de Thérapeutique et de Pharmacie Vétérinaires, Parijs, p. 298 304.

Vanden Eeckhout, A. (1926). Eléments de Thérapeutique Générale Vétérinaire et de Pharmacodynamie, tweede druk, $p$. 438-442.

Van den Eeckhout, P. (2005). '1000 zulke biljetten maken meer effekt dan 10.000 anderen'. Reclame in de Veldstraat voor de eerste wereldoorlog. In: Veldstraat / Gent (H. Defoort en W. De Vuyst, eds.), Gent, p. 107.

Van Naaldwijck, P. (1631). De Paardenvriend. Vertaling door A.C. Oosterhuis van Libri duo Philippicorum, sive de equorum natura, electione, educasione, disciplina et curatione (Leiden), Rotterdam, 1995, p. 139-141,.

Wagenfeld, L. (s.d.). De Bekwame Veearts. Volledig Handboek der Genees- en Verloskunde van het Vee. Vertaling - tweede druk, Leiden, p. 205. 


\section{Van paardenmiddel tot paardendokter De geschiedenis van de paardengenees- kunde}

\section{Tentoonstelling}

15 april t.e.m. 15 mei 2011

Bietje ter Doest - Felix Verhaeghestraat 8A, Waregem

Dagelijks van 14.00 u tot 18.00 u

De evolutie in de paardengeneeskunde, van de niet-gediplomeerde paardenmeester of hoefsmid-veearts tot de dierenarts-universiteitsprofessor wordt geïllustreerd door de familiegeschiedenis van de familie Bouckaert uit Waregem; een mooi voorbeeld hoe het veeartsenberoep zich ontwikkelde. Vele eeuwen waren er in de familie paardenfokkers, hoefsmeden, slagers, dierenartsen en chirurgen aan het werk. Ook het levensverhaal van veearts Hendrik Adriaen uit Poperinge vernemen we. Hij had in het begin van de 20 ste eeuw een bloeiende praktijk. Dankzij de goede bewaring van zijn archief en instrumentarium kunnen we in deze tentoonstelling een getrouw beeld geven van zijn kabinet.

Een andere interessante invalshoek vormen de zogenaamde 'paardenmiddelen'. Vóór de verwetenschappelijking van de diergeneeskunde was de volksveeartsenijkunde erg belangrijk. Er was een sterk geloof in allerhande kruidenmengsels, bezweringsformules en heiligenaanroepingen die zieke dieren zouden beschermen of genezen. Ook elixirs of kruidenlikeuren, zoals het Elixir d'Anvers, kregen een grote populariteit als reddend middel tegen koliek bij paarden. Het aanroepen van heiligen zoals de heilige Brigida of Sint-Elooi en het influisteren van bezweringsformules waren courante praktijken bij de behandeling van dierenziekten. Aanvankelijk hadden de landbouwers maar weinig vertrouwen in de gediplomeerde veeartsen. Ze oordeelden dat ze teveel boekenwijsheid 
bezaten en weinig praktisch waren ingesteld. Heel wat volksgebruiken bleven dan ook doorleven tot in de 20ste eeuw.

De tentoonstelling schenkt ook aandacht aan het wetenschappelijke aspect van de diergeneeskunde. Unieke stukken uit de collecties van de faculteiten diergeneeskunde van Utrecht en Gent worden getoond: de binnenkant van een paardenhoef, vaatafgietsels die wel kunstwerken lijken, vreemde instrumenten uit vorige eeuw, een doorgesneden paardenhoofd, een volledig paardenskelet en nog veel meer.

'Van paardenmiddel tot paardendokter', een tentoonstelling over het verleden van de paardengeneeskunde, werd gerealiseerd door het stadsarchief van Waregem met medewerking van de faculteit diergeneeskunde van de Universiteiten van Gent en Utrecht, de universiteitsbibliotheek van Utrecht en het Museum Morfologie van Gent. Ter gelegenheid van deze tentoonstelling wordt ook het boek 'Van paardenmiddel tot paardendokter' uitgegeven.



